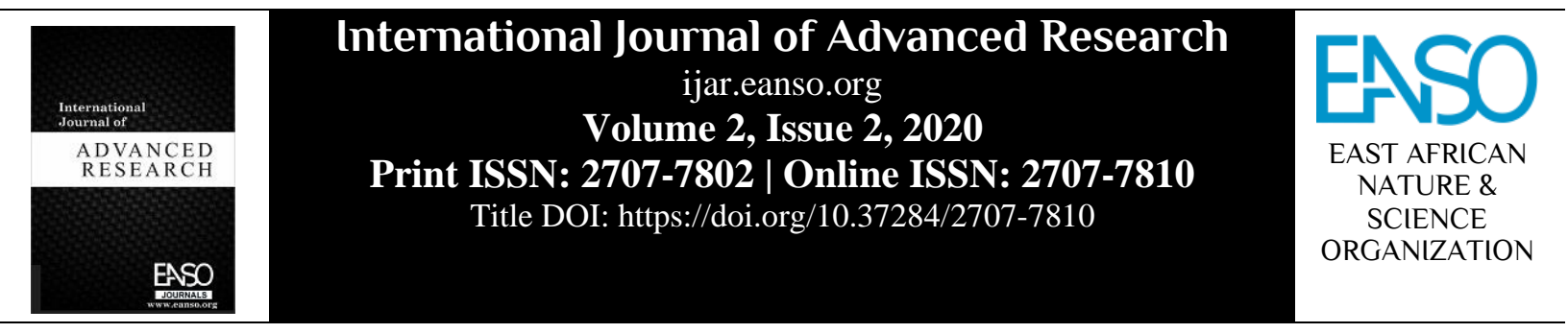

Original Article

\title{
Improving Knowledge Gain in Secondary School Agricultural Education through Supervised Agricultural Experience Programme (SAEP) in Migori County, Kenya
}

\author{
Peter Odhiambo Ongang'a ${ }^{1 *}$, Washington Adede Ochola', \\ Judith Odhiambo' \& Evans Abenga Basweti ${ }^{1}$ \\ ${ }^{1}$ Kisii University, P. O. Box 408-40200 Kisii, Kenya. \\ * ORCID: https://orcid.org/0000-0002-5884-4252. \\ * Author for Correspondence Email: odhiambopeter55@gmail.com.
}

Article DOI: https://doi.org/10.37284/ijar.2.2.230

\section{Publication Date: ABSTRACT}

29 October 2020 This study focused on determining the influence of SAEP on knowledge gain in secondary school agricultural education among Form Three students in

Keywords: Migori County, Kenya. It zeroed on analysing the differences in knowledge

SAEP gained in agriculture between two groups, one taking part in SAEP and the

Learning Outcomes, Knowledge Gain, Agricultural Education, Secondary School Students. other not taking part. It utilised quasi-experimental design, particularly the pre-test and post-test none-equivalent control group design incorporating a sample of 384 forms three agriculture students in Migori County. A test for measuring learning outcomes was used to collect data before and after the programme. Analysis of data was done using SPSS (Version 22). Descriptive statistics were used to present and describe data while inferential statistics were used test hypotheses at $\alpha=0.05$. The study established that there was a statistically significant difference in the acquisition of knowledge of specific agriculture content between secondary school agriculture students exposed to SAEP as opposed to the control group.

\section{APA CITATION}

Ongang'a, P., Ochola, W., Odhiambo, J., \& Basweti E. (2020). Improving Knowledge Gain in Secondary School Agricultural Education through Supervised Agricultural Experience Programme (SAEP) in Migori County, Kenya. International Journal of Advanced Research, 2(2), 6-18. https://doi.org/10.37284/ijar.2.2.230

\section{CHICAGO CITATION}

Ongang'a, Peter, Washington Ochola, Judith Odhiambo, and Evans Basweti. 2020. "Improving Knowledge Gain in Secondary School Agricultural Education through Supervised Agricultural Experience Programme (SAEP) in Migori County, Kenya". International Journal of Advanced Research, 2 (2), 6-18. https://doi.org/10.37284/ijar.2.2.230. 


\section{HARVARD CITATION}

Ongang'a, P., Ochola, W., Odhiambo, J. and Basweti, E. (2020) "Improving Knowledge Gain in Secondary School Agricultural Education through Supervised Agricultural Experience Programme (SAEP) in Migori County, Kenya", International Journal of Advanced Research, 2(2), pp. 6-18. doi: 10.37284/ijar.2.2.230.

\section{IEEE CITATION}

P. Ongang'a, W. Ochola, J. Odhiambo, and E. Basweti, "Improving Knowledge Gain in Secondary School Agricultural Education through Supervised Agricultural Experience Programme (SAEP) in Migori County, Kenya”, IJAR, vol. 2, no. 2, pp. 6-18, Oct. 2020.

\section{MLA CITATION}

Ongang'a, Peter, Washington Ochola, Judith Odhiambo, and Evans Basweti. "Improving Knowledge Gain in Secondary School Agricultural Education through Supervised Agricultural Experience Programme (SAEP) in Migori County, Kenya". International Journal of Advanced Research, Vol. 2, no. 2, Oct. 2020, pp. 6-18, doi:10.37284/ijar.2.2.230.

\section{INTRODUCTION}

Agricultural instruction has changed over time. Apart from the conventional classroom instruction approaches for agricultural education, some countries have shifted how agriculture is taught. Central to this is the reason that the students' perception is changing over time hence the need to move towards modern methods of instruction. Incorporating agricultural programmes in school teaching can change greatly how students view Agriculture and agricultural careers as well as how much they get to know about agricultural processes. In the past, agriculture was offered to the few students that desired career within traditional, production agriculture, but today, agricultural education programmes have been developed as a means to educate the society regarding the centrality of agricultural production outside the classroom setting. Agriculture should therefore not only be viewed as a classroom interaction to make learners acquire high grades in tests but also as a tool to improve future lives through uptakes of related careers. Agriculture is one of the career subjects. School agricultural education programmes should be organised in a way that can make learners see the importance of the subject.

Students' knowledge is one of the key learning outcomes in agricultural education. It can be influenced by a number of factors as Duncan, Broyles and Tech (2004) puts it. As per Dyer and Whittaker (2000), journalists are trained on how to write but are ill-equipped to fully understand their influence in the complex relationship between agricultural producers and consumers. Lichter, Lichter, and Rothman (1991) noted that more than 2 out of 3 participants preferred liberal activist groups of environmental information over more conservative sources. The use of liberal activist groups may create a discrepancy between public understanding and reliable information. If parents are influenced by unreliable reports in the media, they may not encourage their son or daughter to enrol in a high school agriculture class or pursue an agricultural degree in college (Park, 2010).

Students' enrolment in agriculture in schools has been seen to be declining. A potential remedy for this could be providing students with more exposure to agricultural programmes while in school. Such programmes can increase agricultural understanding and stimulate positive agricultural perceptions (Wagler et al., 2007).

Past analyses have made conclusions to the effect that agricultural literacy influences a student's agricultural perceptions. A study evaluating the effectiveness of a swine education program found that the curriculum positively increased the students' knowledge hence attitudes towards the pork industry increased (Wagler et al., 2007). A study conducted in rural Missouri of the USA found a weak positive correlation between agricultural literacy and positive perception towards Agriculture (Wright, Stewart, \& Birkenholz, 1994). The more educated an individual the more they get to know about agriculture and the fewer negative 
stereotypes the individual developed about the subject. It is therefore in order for Kenya to inculcate those programmes that will increase agricultural literacy if the positive perception is to be attained in Kenyan Agriculture.

In the US, the National Future Farmers of America (FFA) Organization is available for all young people enrolled in a secondary agricultural education program with a mission to make a positive difference in the lives of students by developing their potential for premier leadership, personal growth, and career successes. In order to continue to have young people interested in agricultural careers, students must be educated about those programme areas.

The year 2013 study on secondary student's perceptions about Agriculture as a subject in Meru District Kenya gave more insight into this. Based on the findings of the study, it was concluded that students perceive Agriculture as a useful subject to them, school and the surrounding community (Muchiri, Odilla \& Kathuri, 2013). Results from the analysis showed no statistically significant difference in perception of secondary school Agriculture between students of parents living in rural areas and those whose parents lived in the urban set-up. It was concluded that parents' residence did not influence how secondary school Agriculture is perceived by students. It is however worth noting that students residing with their parents in the urban and peri-urban set up do not have much exposure to agricultural activities, hence they may have some negative perceptions about Agriculture.

In a study conducted by Luckey et al. (2013), participants' knowledge in Agriculture increased following their participation in the AgVenture program. It is possible that prior lack of agricultural literacy was a result of the fact that about $32 \%$ of the participants reported that they had no previous agricultural experience. Based on the finding that only $34 \%$ of the participants believed that
Agriculture affected them. It can be concluded that many of the participants did not have a clear understanding of the role that Agriculture plays in society. However, before taking part in AgVenture, the majority of participants had an interest in learning about Agriculture as a subject in school.

\section{METHODOLOGY}

\section{Research Design}

The study used quasi-experimental design (precisely the pre-test and post-test none-equivalent control group design), where subjects are nonrandomly assigned to treatment and control groups. Experimental group members are subjected to a pre-test, take part in the experiment and are given a post-test. The non-equivalent control group receives a pre-test, not subjected to treatment, and then a post-test is done. The control group would have characteristics that resemble the treatment group, but the participants would lack random assignment to this group due to difficulty in doing so (Privitera \& Delzell, 2019).

The study was conducted in Migori County, Kenya.

Cochran's (1977) formula for determining sample size was employed in getting 384 students of Agriculture. The equation for calculating sample size is shown here-in:

Unlimited population: $N=\frac{z^{2} p g}{\varepsilon^{2}}$. Where $z=$ the $\mathrm{z}$ score; $\varepsilon=$ the margin of error; $N=$ population size; $\hat{p}=$ the population proportion

As per this study, the researcher used $95 \%$ confidence with a margin of error of $5 \%$, assuming a population proportion of .5 , and unlimited population size. Bear in mind that $\mathrm{z}$ for a $95 \%$ confidence level is 1.96 from the z-table. Substituting the formula, therefore $; \frac{1.96^{2} * 0.5(1-0.5)}{0.05^{2}}=384.16$ As a result, a sample of 384 was obtained and distributed as indicated in Table 1. 
Table 1: Target population and sample size

\begin{tabular}{lllll}
\hline $\begin{array}{l}\text { School } \\
\text { Type }\end{array}$ & $\begin{array}{l}\text { Number of } \\
\text { Schools }\end{array}$ & $\begin{array}{l}\text { Total Agriculture } \\
\text { Students }\end{array}$ & $\begin{array}{l}\text { Number of } \\
\text { Sampled }\end{array}$ & $\begin{array}{l}\text { Schools } \\
\text { Sample } \\
\text { Size }\end{array}$ \\
\hline Boys' & 13 & 390 & 2 & 48 \\
Girls' & 17 & 420 & 2 & 48 \\
Mixed & 179 & 2,880 & 12 & 288 \\
Total & $\mathbf{2 1 4}$ & $\mathbf{3 , 6 9 0}$ & $\mathbf{1 6}$ & $\mathbf{3 8 4}$ \\
\hline
\end{tabular}

\section{Instrumentation and Data Collection}

A test was used to collect data. The test was constructed using the Likert scale. It collected information on the knowledge in agriculture before implementation and after implementation of the programme. Before the programme began, a teat was given with items addressing knowledge in agriculture. Data were collected to ascertain the student's knowledge in the specific agriculture content. After this, the students were assigned to the experimental and control groups (having only one group in a school to avoid diffusion of information to control groups). The experimental group was instructed about the programme which involved growing of coriander crop. They grew the crop taking part in all agronomic practices from land preparation, planting to harvesting and disposal. The control group did not take part in the programme. After this data was collected again from the two independent groups and compressions made with respect to knowledge in agriculture before and after SAEP.

\section{Data Analysis}

The collected data was first cleaned up for any errors such as incompleteness or inaccurate marking of responses. Data was then coded and recorded to reduce mass for ease of analysis. Data was then entered into the computer for analysis using Statistical Packages for Social Sciences Version 22. Descriptive statistics was used in describing nominal data for this study. Data was further analysed and presented using measures of central tendency, i.e. means and percentages where appropriate.

\section{RESULTS}

\section{Classification of Coriander Crop}

As for this study, the respondents were required to classify the crop on the basis of the edible parts whether roots, stem, flowers, seeds or leaves. Coriander crop is a leafy vegetable because the consuming part is the leaf. As shown in Appendix $1,33.3 \%$ of the respondents in the experimental group were not able to classify it correctly while $66.7 \%$ were able to correctly classify the crop as reported before the SAE programme. After the SAE programme, all the respondents in the experimental group were able to correctly classify the crop. For the control group, $27.6 \%$ of the respondents were not able to classify it correctly while $72.4 \%$ were able to correctly classify the crop prior to SAE programme. After the SAE programme, 27.6\% were not able to classify it correctly while $72.4 \%$ were able to classify it correctly. It can be seen that after the intervention, all the respondents in the experimental group were able to classify the crop correctly (mean of 2.00) compared to a mean of 1.67 before, and this could be attributed to the experimental exposure effect. It means therefore that the students learned something during the period they were engaged with the crop production practices.

\section{Responses Regarding What Determines Planting Depth of Coriander Crop}

The respondents were asked to indicate what determines the planting depth for coriander crop. When seeds are planted at the right depth, they have a higher likelihood of growing into hardy 
seedlings and improved germination percentages (Welbaum, 2015). As for this study, the respondents were required to indicate what determines the depth of planting. Coriander crop is a small-seeded crop which should not be deeply planted. As indicated in Appendix 1, the majority $(65.6 \%)$ of the respondents in the experimental group were not able to indicate the correct factor determining planting depth while only about a third (34.4\%) were able to correctly indicate it. After the experimental programme, 21.4 per cent of the respondents in the experimental group were able to indicate the correct factor determining planting depth while the majority (78.6\%) were unable to correctly indicate it. As for the control group, the same number as in the experimental group $(65.6 \%$ and $34.4 \%$ ) respectively were able to indicate it wrong and correct before the programme. After the programme, $53.6 \%$ and $46.4 \%$ were able to wrongly and correctly indicate what determines planting depth (Appendix 1). Due to the intervention, therefore, there was a larger increase in the number of respondents who were able to correctly tell what determines the planting depth in the experimental group than the control group form a low mean of 1.34 to a high mean of 1.79 . The indication is that the students who took part in growing the crop were able to place it at the right depth. However, there was also a small increase in the number of those in the control group who could correctly indicate the determinant of the depth of planting from 1.34 to 1.46 which is low to moderate, an indication that some research work was done by this group after the pre-test.

\section{Responses on Place where Coriander Crop is Grown}

The respondents were needed to indicate where the crop is planted. As Appendix 1 shows, before the programme, most $(98.4 \%)$ of the respondents in the experimental group were could not correctly identify where it is grown while only a paltry $1.6 \%$ were able to correctly indicate where the crop is established. After the SAE programme, very few
$(8.9 \%)$ of the respondents in the experimental group were unable to indicate the correct place of planting while the majority $(91.1 \%)$ were able to correctly indicate where it is grown. This is an increase in the score from 1.02 pre-test to 1.91 post-test. In the control group before SAEP, $95.8 \%$ were unable to correctly indicate where the crop is grown while only $4.1 \%$ were able to correctly indicate that. After taking part in the SAE programme, $75.0 \%$ and $25.0 \%$ of the respondents indicated wrongly and correctly, respectively, where this crop is grown. This showed a pre-test knowledge mean of 1.04 and a post-test mean of 1.25 , both of which were very low (Appendix 1). SAE programme, therefore, had a hugger impact on the student's knowledge of where the crop is grown.

\section{List of Possible Weeds in Coriander Crop Farm}

As shown in Appendix 1, before the programme, the majority $(54.7 \%)$ of the respondents in the experimental group could not correctly identify that all the weeds listed could attack coriander while the other $45.3 \%$ were able to correctly identify that all these weeds could be found in the coriander far. After the initiative to grow coriander in the school farm, very few $(1.0 \%)$ of the respondents in the experimental group were still not able to indicate the correct answer while the majority (99.0\%) were able to correctly indicate the answer about weeds, an indication of pre-test and post-test scores of 1.45 and 1.99 respectively. In the control group, $65.6 \%$ were unable to correctly indicate the answer concerning weeds, while only $34.4 \%$ were able to correctly indicate that before the intervention. After the SAE intervention, there was no change in the number of respondents who were able to identify the correct and wrong answer, that is, the percentages were still at $65.6 \%$ and $34.4 \%$ for wrong and correct answer respectively, showing a pre-test score of 1.34 and a post-test score of 1.34 (Appendix 1). This is an indication that the students who took part in growing the crop were able to identify the weeds in the field, unlike their counterparts in the control groups. 


\section{Knowledge of Most Recommended Planting Method for Coriander Crop}

It can be seen from Appendix 1 that before the $\mathrm{SAE}$ programme, slightly more than half $(51.0 \%)$ of the respondents in the experimental group could not correctly identify the correct planting method for coriander while 49.0 per cent correctly identified the most recommended method of planting. After growing coriander, all (100.0\%) of the respondents in the experimental group were able to identify the correct answer with reference to the planting method. This is an indication of a moderate score of 1.49 pre-test and a very high post-test score of 2.00 . On the other hand, for the control group, 34.9\% were unable to correctly indicate the right planting method, while only $65.1 \%$ were able to correctly indicate the method. After the SAE programme, there was no change in the number of respondents who were able to identify the correct and wrong answers, that is, the percentages were still at $34.9 \%$ and $65.1 \%$ for wrong and correct answer respectively with reference to the planting method, showing a score of 1.65 pre-tests and post-test (Appendix 1). In the sub-Saharan Africa context, traditional methods such as broadcasting are common where seeds are randomly scattered in the field. In this method, germination percentages tend to be poorer with forcing the farmers to try to compensate by using more seeds. The problem with higher seed rate is that it leads to spending more money on seeds without the corresponding yield increases (Agriculture for Impact, 2019).

\section{Responses on Requirements Necessary for Proper Growth of Coriander Crop}

Coriander, just like any other crop requires certain important conditions for proper growth to occur. The study therefore required respondents to show the right answer as per these requirements. All the first three were necessary; hence the correct response would all of them. From Appendix 1, it can be reported that before the SAE programme, about half $(52.6 \%)$ of the respondents in the experimental group could not correctly identify the requirements necessary for the proper growth of coriander crop while $47.4 \%$ correctly identified requirements necessary for proper growth of coriander crop. After growing coriander, only $0.5 \%$ of the respondents in the experimental group were still unable to show the requirements necessary for proper growth of coriander crop while almost all (99.5\%) of the respondents in the experimental group were able to identify the correct answer with reference to growth requirements. This was an increase in the scores from a moderate of 1.47 pretest mean to a very high post-test mean of 1.99 . On the other hand, for the control group, $49.0 \%$ were unable to correctly indicate the right growth conditions while only $51.0 \%$ were able to correctly indicate the conditions (Appendix 1). After the SAE programme, there was no change in the number of respondents who were able to identify the correct and wrong answer, showing a moderate pre-test and post-test score means of 1.51 in both cases.

\section{Knowledge of By-products of Coriander Crop}

After harvesting, coriander can be utilised in various ways by means of the end products. The study asked respondents to show the right answer as per these by-products listed. There were two correct options except for livestock feeds. From Appendix 1, it can be seen that before the SAE programme, the majority $(71.9 \%)$ of the respondents in the experimental group did not correctly identify the by-products of coriander crop while $28.1 \%$ correctly identified the by-products of coriander crop. After the SAEP venture, only $0.5 \%$ of the respondents in the experimental group were still unable to correctly identify the by-products of the coriander crop while the majority $(99.5 \%)$ of the respondents in the experimental group were able to correctly identify the by-products of coriander crop. This is an increase from a low pre-test score of 1.28 to a very high post-test score of 1.99 . On the other hand, for the control group, $62.5 \%$ were unable to correctly identify the by-products of the coriander 
crop while only $37.5 \%$ were able to correctly identify the by-products of the coriander crop. However, after the SAE programme, there was a marginal change in the number of respondents who were able to identify the correct and wrong answer as those who identified the wrong answer reduced to $58.3 \%$ while those who were able to identify the right answer increased to $47.4 \%$, giving a mean of 1.38 for the pre-test and post-test categories. It can therefore be mentioned that the SAEP had an influence on the respondent's ability to identify the by-products as they were able to interact with the crop at post-harvest handling.

\section{Opinion on Field Production Practice in Coriander Production}

Coriander production entails a number of field practices. The respondents were therefore asked to identify the right answer as per these field production practices. From Appendix 1, it is reported that before the SAEP venture, $44.8 \%$ of the respondents in the experimental group were not able to identify the correct answer while 55.2\% correctly identified the right answer for field production practices in coriander crop. After the SAEP venture, only $1.6 \%$ of the respondents in the experimental group did not correctly identify the answer while the majority (98.4\%) of the respondents in the experimental group were able to correctly identify the answer. This was an increase from a moderate pre-test score of 1.55 to a very high post-test score of 1.98. For the control group, $46.9 \%$ were unable to correctly identify the field production practices while the majority $(53.1 \%)$ were able to correctly identify the answer before the SAEP. However, after the SAEP, there was a small change in the number of respondents who were able to identify the correct and wrong answer as those unable to identify the correct answer increased to $49.5 \%$ while those who were able to identify the right answer decreased to $49.5 \%$ from 53.1 per cent showing a constant and moderate pre-test and a post-test score of 1.51 in both cases. According to Seeds of Gold (2018), coriander is easy to grow crop hence requires minimum maintenance in terms of field practices. It has a few incidents of pests and diseases attack and it does not require labour intensive.

\section{How Long it Takes Coriander to Mature in Migori County}

As seen in Appendix 1, before the SAE programme was implemented in schools, $47.4 \%$ of the respondents in the experimental group were not able to identify the correct length of time the crop grows to maturity while $52.6 \%$ able to identify the correct length of time the crop grows to maturity. After the SAEP was implemented, only $1.0 \%$ of the respondents in the experimental group did not correctly identify the answer while the majority $(99.0 \%)$ of the respondents in the experimental group were able to correctly identify the answer, an increase in mean scores from 1.51 to 1.99 for pretest and post-test categories respectively. For the control group, $56.3 \%$ were unable to correctly identify the field production practices while fewer (43.7\%) were able to correctly identify the answer before the SAEP. After the SAEP, 52.1\% of the respondents in the control group were unable to identify the right answer while $47.9 \%$ were able to identify the right answer with reference the length of time the crop takes to mature in Migori County, showing the same pre-test and post-test mean of 1.44. It can be seen therefore that the number of respondents who were able to identify the right answer increased significantly in the experimental group due to the intervention while for the control group, there was no significant change, but it is worth noting that the number increased with respect to the ability to identify the right answer.

\section{Field Post-harvest Practice in Coriander Production}

Post-harvest practices include the handling of the crop after harvesting before the sale or use at home. Form Three Agriculture students were asked to identify the various post-harvest practices in 
coriander production among the options of drying, cleaning the soil, watering and dusting, the right answer is cleaning the soil only. Being that this crop is uprooted at maturity, it should be cleaned of the soil before disposal. Cleaning is necessary so as to have clean produce for market or home consumption. As shown in Appendix 1,78.1\% of the respondents in the experimental group were not able to identify the correct post-harvest practice while $21.9 \%$ able to identify the correct postharvest practice before the SAEP. After the SAEP, only $1.0 \%$ of the respondents in the experimental group failed to identify the correct post-harvest practice while the majority $(99.0 \%)$ of the respondents identified the correct post-harvest practice, showing an increase from a very low pretest score of 1.22 to a very high post-test score of 1.99. In the control group, $78.6 \%$ were unable to correctly identify the post-harvest practices while about a fifth (21.4\%) was able to correctly identify the answer before the SAEP. After the SAEP, $83.3 \%$ of the respondents in this group were unable to identify the right answer while $16.7 \%$ were able to identify the right answer with reference to the post-harvest practice in coriander crop, indicating a pre-test and post-test score of 1.21 in both cases. Based on the result, there was a very significant increase in the number of students who could identify the right post-harvest practice in the experimental group due to the SAEP while for the control group there was no significant change but rather a reduction in the number. These findings concur with Hadsock (2006) who found out that involving students in farm practices greatly improved their knowledge in carrying out agricultural activities in farm crop production.

\section{Number of Seeds per Hole Recommended for Planting of Coriander Crop}

Planting is a skill and how it is done will have an overall bearing on crop performance and ultimate yield. Coriander crops, just like any other has many options of planting among them row planting, broadcasting or drilling. It is a general recommendation that row planting is adopted for crops where possible because its advantages overweigh those of other methods. This recommendation is also adopted for the coriander crop. The respondents were therefore asked to identify the most recommended planting method for coriander crop and the responses are as shown in Appendix 1. It can be seen that majority $(62.5 \%)$ of the respondents in the experimental group were not able to correctly identify the most recommended planting method for coriander crops while $32.3 \%$ were able to correctly identify the most recommended planting method for coriander crop before the SAEP. After the programme, only $1.6 \%$ of the respondents in the experimental group were still unable to correctly identify the most recommended planting method while the majority (98.4\%) of the respondents in the experimental group were able to correctly identify the most recommended planting method, an indication of an increase from pre-test score of 1.38 to post-test score of 1.99 . In the control group, $56.8 \%$ were unable to identify the most recommended planting method for coriander crops while less than half (43.2\%) were able to correctly identify the most recommended planting method before the SAEP. After the SAEP, $51.5 \%$ of the respondents in the control group were unable to identify the right answer while $48.5 \%$ were able to identify the right answer with reference to the most recommended planting method for coriander crop showing no difference in the pre-test and post-test score of 1.43 (Appendix 1). It can be said therefore that the engagement with the programme had a greater impact on the ability of the respondents in the experimental group to identify the right planting method than those in the control group. The experimental group was able to actually grow the crop hence actual practice following instructions from the teacher and the researcher. 


\section{Number of Times Coriander Crop should be Weeded}

Weeding is an agronomic practice that ensures the field is weed-free to avoid undue competition for nutrients and other resources. The crop, being an annual crop with a short growing period should only be weeded once if the field had been prepared free of weeds before planting. The respondents were therefore asked to indicate the number of times coriander crop should be weeded and the results are as shown in Appendix 1. It can be reported that the majority $(62.5 \%)$ of the respondents in the experimental group could not correctly identify the number of times coriander crops should be weeded while $37.5 \%$ were able to correctly identify the number of times coriander crop should be weeded before the SAEP. After taking part in the SAEP, only $0.5 \%$ of the respondents in the experimental group could not correctly identify the number of times coriander crop should be weeded while the majority $(99.5 \%)$ of the respondents correctly identified the number of times coriander crop should be weeded which showed an increase in the index score from a pretest of 1.38 to a post-test score of 1.99. In the control group, $56.8 \%$ were unable to correctly identify the number of times coriander crop should be weeded while $(43.2 \%)$ correctly indicated the number of times coriander crop should be weeded, before the SAEP showing no change in index scores of 1.48 before and after the SAEP. After the SAEP, there was no change in the number of respondents who correctly and incorrectly indicated the number of times coriander crop should be weeded. It can consequently be said that the programme had a lot of impact in the experimental group while it had no impact at all in the control group based on the ability to properly identify the number of times to weed coriander crop.

\section{Procedure in Coriander Harvesting}

The respondents in this study were asked to indicate the procedure in the harvesting of coriander among the options of cutting the plant, uprooting and plucking of leaves and the results from this are displayed in Appendix 1. About one fifth (21.9\%) of the participants taking part in SAEP did not correctly identify the harvesting procedure while the majority $(78.1 \%)$ correctly identified the harvesting procedure in coriander crop production before the SAEP was implemented. After implementing the SAEP, only $0.5 \%$ of the respondents in this group were unable to identify the procedure for harvesting while almost all (99.5\%) were able to identify the harvesting procedure showing an increase in the scores from pre-test score of 1.79 to post-test score of 1.99. For those who did not take part in SAEP, 22.9 percent did not correctly identify the procedure of harvesting coriander while most $(77.1 \%)$ of them correctly identified the procedure of harvesting, before the SAEP. After the SAEP, there was a minimal change in the number of respondents who incorrectly and correctly indicated the procedure of harvesting coriander, as shown by $22.4 \%$ and $77.6 \%$ in that order showing a high score of 1.78 in the pre-test and post-test respectively. It is seen therefore that the programme had an influence on the experimental group's ability to identify the right answer while the lack of it in the control group could have led to the no-change scenario in the ability of respondents to identify the right answer.

\section{Mean Index of Student's Knowledge in Agriculture}

There were 14 test items used to measure the student's knowledge in Agriculture. The mean index score from these items can be summarised as shown in Table 2. 
Table 2: Mean Index of Student's Knowledge in Agriculture

\begin{tabular}{|c|c|c|c|c|c|}
\hline Indicator Statistics & Category & $\mathbf{N}$ & Mean & $\begin{array}{l}\text { Std. } \\
\text { Dev. }\end{array}$ & $\begin{array}{l}\text { Std. } \\
\text { Err. }\end{array}$ \\
\hline Average of student's knowledge in Agriculture & Experimental & 192 & 1.4576 & .17651 & .01274 \\
\hline before SAEP & Control & 192 & 1.4769 & .20097 & .01450 \\
\hline Average of student's knowledge in Agriculture & Experimental & 192 & 1.9603 & .10808 & .00780 \\
\hline after SAEP & Control & 192 & 1.6328 & .22476 & .01622 \\
\hline
\end{tabular}

As can be seen from Table 2, the experimental group had a combined mean of $1.46(S D=.18)$ and a standard error of the mean of 0.13 in Agriculture before the SAEP. This mean is interpreted as moderate. However, after the SAEP, the group had a mean of $1.96(S D=0.11)$ and a standard error of the mean of .01 in Agriculture content knowledge. This mean is interpreted as very high. For the control group, mean of $1.48(S D=0.20)$ and a standard error of the mean of .01 in Agriculture before the SAEP. This mean is also interpreted as moderate. After the SAEP, this group had a mean of $1.63(S D=0.22)$ and a standard error of the mean of .02 in Agriculture content knowledge. This mean is interpreted as high. It can be said therefore that the students who took part in SAEP had a generally bigger increase in Agriculture content knowledge than those who did not take part. It can also be seen that the control group had a higher standard deviation and a higher standard error of the mean, showing that the control group was more spread out in knowledge than the experimental group and with a higher variability. These findings concur with that of Amuriyaga, Hudu and Abujaja (2018) which looked at the impact of project method in teaching Agriculture. The study reported that the intervention had a significant contribution to improving the students' knowledge of nursery practice and general crop production practices. It concluded that the students reported higher knowledge indices after the project compared to before it.

\section{Testing of Hypothesis on Students' Knowledge in Agriculture}

The first objective of the study was to find out the difference in students' knowledge in Agriculture between secondary school Agriculture students exposed to SAE and those not exposed to SAE. To measure this objective, a null hypothesis was formulated. The first null hypothesis stated that: there is no statistically significant difference in the acquisition of knowledge of specific Agriculture content between secondary school Agriculture students exposed to SAE and those not exposed to SAE. To test the hypothesis, a one-way ANOVA and an independent sample t-test was computed at 95\% confidence level. One-way ANOVA test was done post-SAEP to check the similarities (or differences) in group means and results are presented in Table 3.

Table 3: Post SAEP ANOVA Results for Similarities in Knowledge in Agriculture

\begin{tabular}{lllllll}
\hline & & Sum of Squares & DF & Mean Square & F & Sig. \\
\hline Experimental & Between Groups & .012 & 7 & .016 & 1.494 & .172 \\
& Within Groups & 2.024 & 184 & .011 & & \\
\multirow{5}{*}{ Control } & Total & 2.036 & 191 & & & \\
& Between Groups & .385 & 7 & .055 & 1.617 & .133 \\
& Within Groups & 6.256 & 184 & .034 & & \\
& Total & 6.641 & 191 & & & \\
\hline
\end{tabular}


For the experimental group, the 24 respondents from each school presented the following means in knowledge in Agriculture: Masara had 1.92 ( $S D=$ $0.04)$; Nyango had $1.89(S D=0.06)$; Sori had 1.87 $(S D=0.20)$; Nyamome had $1.93(S D=0.11)$; Tuk Jowi had $1.93(S D=0.06)$; Agenga had $1.91(S D=$ $0.04)$; Kubweye had $1.91(S D=0.04)$; and Nyamuga had $1.92(S D=0.14)$. The difference in knowledge in Agriculture, therefore, was insignificant, $F(7,184)=1.49, p=.17$.

For the control group, the 24 respondents from each school had the following means: Abwao had 1.6 $(S D=0.27)$; Kakrao gave $1.59(S D=0.17)$; Akala had $1.73(S D=0.16)$; Moi Suba had $1.75(S D=$ $0.16)$; Bishop Okinda had $1.67(S D=0.16)$; Onyalo had $1.33(S D=0.20)$; Nyarach had $1.73(S D=$ $0.15)$; Nyikendo had $1.73(S D=0.15)$. The difference in knowledge in Agriculture among schools, therefore, was insignificant, $F(7,184)=$ $1.62, p=.13$. These findings confirm that the eight schools in each group had means that were not statistically different. This can further be interpreted to mean that the schools in the two categories were reporting means that were not so far apart after the programme.

To determine if there were differences in knowledge in Agriculture between experimental and control groups, an independent sample t-test $\mathrm{w}$ as done and the results are presented in Table 4.

Table 4: T-test for the Differences in Knowledge in Agriculture between Experimental and Control Groups

\begin{tabular}{|c|c|c|c|c|c|c|c|c|c|c|}
\hline \multicolumn{11}{|c|}{ Independent Samples Test } \\
\hline & & \multicolumn{2}{|c|}{$\begin{array}{l}\text { Levene's Test } \\
\text { for Equality of } \\
\text { Variances }\end{array}$} & \multicolumn{7}{|c|}{ t-test for Equality of Means } \\
\hline & & $\mathbf{F}$ & Sig. & $\mathbf{t}$ & df & $\begin{array}{l}\text { Sig. (2- } \\
\text { tailed) }\end{array}$ & $\begin{array}{l}\text { Mean } \\
\text { Diff }\end{array}$ & $\begin{array}{l}\text { Std. } \\
\text { Error } \\
\text { Diff }\end{array}$ & $\begin{array}{l}95 \% \text { CI } \\
\text { Lower }\end{array}$ & Upper \\
\hline $\begin{array}{l}\text { Overall } \\
\text { knowledge }\end{array}$ & $\begin{array}{l}\text { Equal variances } \\
\text { assumed }\end{array}$ & 3.735 & .054 & -1.002 & & .317 & -.01935 & .01930 & -.05730 & .01861 \\
\hline before SAEP & $\begin{array}{l}\text { Equal variances } \\
\text { not assumed }\end{array}$ & & & -1.002 & 375.741 & .317 & -.01935 & .01930 & -.05730 & .01861 \\
\hline $\begin{array}{l}\text { Overall } \\
\text { knowledge }\end{array}$ & $\begin{array}{l}\text { Equal variances } \\
\text { assumed }\end{array}$ & $\begin{array}{l}88.67 \\
9\end{array}$ & .000 & & 382 & .000 & .42746 & .01800 & .39207 & .46284 \\
\hline after SAEP & $\begin{array}{l}\text { Equal variances } \\
\text { not assumed }\end{array}$ & & & 23.749 & 274.848 & .000 & .42746 & .01800 & .39202 & .46289 \\
\hline
\end{tabular}

Independent sample t-test was done to compare the group means. It was necessary to do a pre-test to ensure that there was equality of means between the experimental and control groups prior to the programme implementation. As can be seen from Table 4.37, pre-test independent sample t-test revealed that the group means for experimental $(M$ $=1.46, S D=0.08)$, and control $(M=1.47, S D=$ $0.20)$ groups were not statistically different on the knowledge in Agriculture, $t(382)=-1.00, p=.32$. Post-SAEP t-test revealed that there was a statistically significant difference in students' knowledge in Agriculture between the experimental and control groups $(M=1.96, S D=$ $0.11 \& M=1.63, S D=0.23$ respectively), $t(274.85)$ $=23.75, p=.001$. This implies after the SAEP, there was a statistically significant difference in knowledge in Agriculture between students taking part and those not taking part. Consequently, the null hypothesis that there is no statistically significant difference in the acquisition of knowledge of specific Agriculture content between secondary school Agriculture students exposed to $\mathrm{SAE}$ and those not exposed to SAE is rejected. 


\section{CONCLUSION AND RECOMMENDATION}

The study concluded that when students are taught agriculture through SAEP, they would acquire higher knowledge than those taught through the conventional methods. In order to ensure that the objective of ensuring that learners acquire necessary practical knowledge in solving agricultural problems, SAEP should be adopted as one of the teaching approaches in secondary schools.

\section{REFERENCES}

Agriculture for Impact. (2019). Seed spacing. Retr ieved November 6, 2019 from https://ag4impa ct.org/sid/ecological-intensification/precisionagriculture/seed-spacing/

Amuriyaga, I. D., Hudu, Z., \& Abujaja, A. M. (2018). Effectiveness of project method of teaching on agricultural knowledge and skills acquisition among agricultural science students of Awe Senior High School in the Upper East Region, Ghana. World Journal of Educational Research and $R$ eviews, 4(1), 062-075.

Duncan, D. W., Broyles, T. W., \& Tech, V. (2004). An evaluation of student knowledge and perceptions toward agriculture before and after attending a governor's school for agriculture. Journal of Southern Agricultural Education Research, 54(1), 280-292.

Dyer, J. E., \& Whittaker, B. K. (2000). Identifying sources of bias in agricultural news reporting. Journal of Agricultural Education, 41(4), 125-133.
Hadsock, Q. C. (2006). The impact of middle school agricultural education programs as perceived by Georgia. Masters Thesis, University of Georgia.

Lichter, S. R., Lichter, L. S., \& Rothman, S. (1991). Watching America. New York: Prentice Hall Press.

Luckey, A. N., Murphrey, T. P., Cummins, R. L., \& Edwards, M. B. (2013). Assessing youth perceptions and knowledge of Agriculture: the impact of participating in an $\mathrm{AgVenture}$ progr am. Journal of Extension, 51(3), 6.

Muchiri, J. M., Odilla, G. A., \& Kathuri, N. J. (2013). Students 'perception Of Secondary School Agriculture: A Case of Meru Central District, Kenya. Asian Journal of Social Sciences and Humanities, 2(4), 129-135.

Privitera, G. J., \& Delzell, L. A. (2019). QuasiExperimental and Single-Case Experimental Designs. Research methods for education, 333370.

Wagler, S. E., Rusk, C. P., Blomeke, C. R., Talbert, B. A., Richert, B. T., \& Latour, M. A. (2007). An Evaluation of Attitude Change by Participation in an Elementary Educational Swine Curriculum. NACTA Journal, 38-43.

Welbaum, G. E. (2015). Vegetable history, nomenclature, and classification. In Vegetable Production and Practices (pp. 1-15). CABI

Wright, D., Stewart, B. R., \& Birkenholz, R. J. (1994). Agricultural awareness of eleventhgrade students in rural schools. Journal of Agricultural Education, 35(4), 55-60. 


\section{APPENDIX}

\section{Appendix 1: Respondent's knowledge in Agriculture}

\begin{tabular}{|c|c|c|c|c|c|c|c|c|c|c|c|c|c|}
\hline \multirow[t]{3}{*}{ Question } & \multirow[t]{3}{*}{$\begin{array}{l}\text { Grouping } \\
\text { category }\end{array}$} & \multicolumn{6}{|c|}{$\begin{array}{l}\text { Pre-experiment } \\
\text { Opinion }\end{array}$} & \multicolumn{6}{|c|}{$\begin{array}{l}\text { Post experiment } \\
\text { Opinion }\end{array}$} \\
\hline & & \multicolumn{2}{|c|}{ Wrong } & \multicolumn{2}{|c|}{ Correct } & \multirow{2}{*}{$\begin{array}{c}\text { Total } \\
\mathbf{f}\end{array}$} & \multirow[t]{2}{*}{ Mean } & \multicolumn{2}{|c|}{ Wrong } & \multicolumn{2}{|c|}{ Correct } & \multirow{2}{*}{$\begin{array}{l}\text { Total } \\
\mathbf{f}\end{array}$} & \multirow[t]{2}{*}{ Mean } \\
\hline & & $\mathbf{f}$ & $\%$ & $\mathbf{F}$ & $\%$ & & & $\mathbf{f}$ & $\%$ & $\mathbf{F}$ & $\%$ & & \\
\hline \multirow[t]{2}{*}{ How would you classify coriander? } & Experimental & 64 & 33.3 & 128 & 66.7 & 192 & 1.67 & 0 & 0 & 192 & 100 & 192 & 2.00 \\
\hline & Control & 53 & 27.6 & 139 & 72.4 & 192 & 1.72 & 53 & 27.6 & 139 & 72.4 & 192 & 1.72 \\
\hline \multirow{2}{*}{$\begin{array}{l}\text { What determines planting depth of coriander } \\
\text { crop? }\end{array}$} & Experimental & 126 & 65.6 & 66 & 34.4 & 192 & 1.34 & 41 & 21.4 & 151 & 78.6 & 192 & 1.79 \\
\hline & Control & 126 & 65.6 & 66 & 34.4 & 192 & 1.34 & 103 & 53.6 & 89 & 46.4 & 192 & 1.46 \\
\hline \multirow[t]{2}{*}{ Where is coriander grown? } & Experimental & 189 & 98.4 & 3 & 1.6 & 192 & 1.02 & 17 & 8.9 & 175 & 91.1 & 192 & 1.91 \\
\hline & Control & 184 & 95.8 & 8 & 4.2 & 192 & 1.04 & 144 & 75 & 48 & 25 & 192 & 1.25 \\
\hline \multirow[t]{2}{*}{ Possible weeds on coriander farm } & Experimental & 105 & 54.7 & 87 & 45.3 & 192 & 1.45 & 2 & 1 & 190 & 99 & 192 & 1.99 \\
\hline & Control & 126 & 65.6 & 66 & 34.4 & 192 & 1.34 & 126 & 65.6 & 66 & 34.4 & 192 & 1.34 \\
\hline \multirow{2}{*}{$\begin{array}{l}\text { The most recommended planting method for } \\
\text { coriander crop }\end{array}$} & Experimental & 98 & 51 & 94 & 49 & 192 & 1.49 & 0 & 0 & 192 & 100 & 192 & 2.00 \\
\hline & Control & 67 & 34.9 & 125 & 65.1 & 192 & 1.65 & 67 & 34.9 & 125 & 65.1 & 192 & 1.65 \\
\hline \multirow{2}{*}{$\begin{array}{l}\text { Which is necessary for proper growth to occur } \\
\text { in coriander? }\end{array}$} & Experimental & 101 & 52.6 & 91 & 47.4 & 192 & 1.47 & 1 & 0.5 & 191 & 99.5 & 192 & 1.99 \\
\hline & Control & 94 & 49 & 98 & 51 & 192 & 1.51 & 94 & 49 & 98 & 51 & 192 & 1.51 \\
\hline \multirow{2}{*}{$\begin{array}{l}\text { Coriander crop can be made into the following } \\
\text { EXCEPT: }\end{array}$} & Experimental & 138 & 71.9 & 54 & 28.1 & 192 & 1.28 & 1 & 0.5 & 191 & 99.5 & 192 & 1.99 \\
\hline & Control & 120 & 62.5 & 72 & 37.5 & 192 & 1.38 & 112 & 58.3 & 80 & 47.7 & 192 & 1.38 \\
\hline \multirow{2}{*}{$\begin{array}{l}\text { Which is a field production practice in } \\
\text { coriander production? }\end{array}$} & Experimental & 86 & 44.8 & 106 & 55.2 & 192 & 1.55 & 3 & 1.6 & 189 & 98.4 & 192 & 1.98 \\
\hline & Control & 90 & 46.9 & 102 & 53.1 & 192 & 1.51 & 95 & 49.5 & 97 & 50.7 & 192 & 1.51 \\
\hline \multirow{2}{*}{$\begin{array}{l}\text { The average length of time (in months) it } \\
\text { takes coriander to mature in Migori County }\end{array}$} & Experimental & 91 & 47.4 & 101 & 52.6 & 192 & 1.53 & 2 & 1 & 190 & 99 & 192 & 1.99 \\
\hline & Control & 108 & 56.3 & 84 & 43.7 & 192 & 1.44 & 100 & 52.1 & 92 & 47.9 & 192 & 1.44 \\
\hline \multirow{2}{*}{$\begin{array}{l}\text { Which is a field post-harvest practice in } \\
\text { coriander production? }\end{array}$} & Experimental & 150 & 78.1 & 42 & 21.9 & 192 & 1.22 & 2 & 1 & 190 & 99 & 192 & 1.99 \\
\hline & Control & 151 & 78.6 & 41 & 21.4 & 192 & 1.21 & 160 & 83.3 & 32 & 16.7 & 192 & 1.21 \\
\hline \multirow{2}{*}{$\begin{array}{l}\text { How many seeds per hole are recommended } \\
\text { for planting of coriander crop? }\end{array}$} & Experimental & 120 & 62.5 & 72 & 32.5 & 192 & 1.38 & 3 & 1.6 & 189 & 98.4 & 192 & 1.98 \\
\hline & Control & 109 & 56.8 & 83 & 43.2 & 192 & 1.43 & 99 & 51.5 & 93 & 48.6 & 192 & 1.43 \\
\hline \multirow{2}{*}{$\begin{array}{l}\text { How many times should you weed a coriander } \\
\text { crop to maturity? }\end{array}$} & Experimental & 120 & 62.5 & 72 & 37.5 & 192 & 1.38 & 1 & 0.5 & 191 & 99.5 & 192 & 1.99 \\
\hline & Control & 109 & 56.8 & 82 & 43.2 & 192 & 1.48 & 109 & 56.8 & 82 & 43.2 & 192 & 1.48 \\
\hline
\end{tabular}


International Journal of Advanced Research, Volume 2, Issue 2, 2020

Article DOI: https://doi.org/10.37284/ijar.2.2.230

\begin{tabular}{|c|c|c|c|c|c|c|c|c|c|c|c|c|c|}
\hline \multirow[t]{3}{*}{ Question } & \multirow[t]{3}{*}{$\begin{array}{l}\text { Grouping } \\
\text { category }\end{array}$} & \multicolumn{6}{|c|}{$\begin{array}{l}\text { Pre-experiment } \\
\text { Opinion }\end{array}$} & \multicolumn{6}{|c|}{$\begin{array}{l}\text { Post experiment } \\
\text { Opinion }\end{array}$} \\
\hline & & \multicolumn{2}{|c|}{ Wrong } & \multicolumn{2}{|c|}{ Correct } & \multirow{2}{*}{$\begin{array}{c}\text { Total } \\
\mathbf{f}\end{array}$} & \multirow[t]{2}{*}{ Mean } & \multicolumn{2}{|c|}{ Wrong } & \multicolumn{2}{|c|}{ Correct } & \multirow{2}{*}{$\begin{array}{l}\text { Total } \\
\text { f }\end{array}$} & \multirow[t]{2}{*}{ Mean } \\
\hline & & f & $\%$ & $\mathbf{F}$ & $\%$ & & & f & $\%$ & $\mathbf{F}$ & $\%$ & & \\
\hline \multirow{2}{*}{$\begin{array}{l}\text { Which is not a type of record kept for } \\
\text { coriander production? }\end{array}$} & Experimental & 30 & 15.6 & 162 & 84.4 & 192 & 1.84 & 0 & 0 & 192 & 100 & 192 & 2.00 \\
\hline & Control & 30 & 15.6 & 162 & 84.4 & 192 & 1.84 & 31 & 16.1 & 161 & 83.9 & 192 & 1.84 \\
\hline \multirow{2}{*}{$\begin{array}{l}\text { Which of the following is a procedure in } \\
\text { coriander harvesting? }\end{array}$} & Experimental & 42 & 21.9 & 150 & 78.1 & 192 & 1.79 & 1 & 0.5 & 191 & 99.5 & 192 & 1.99 \\
\hline & Control & 44 & 22.9 & 148 & 77.1 & 192 & 1.78 & 53 & 22.4 & 139 & 77.6 & 192 & 1.78 \\
\hline
\end{tabular}

